ISSN: $1492-3831$

Vol. 2, No. 2 ( January, 2002)

\title{
A Top Down Strategy to Enhance Information Tech- nologies into Israeli Higher Education
}

Sarah Guri-Rosenblit

The Open University of Israel

\begin{abstract}
This article examines the integration of the new information technologies (IT) into Israeli higher education, and most particularly its research universities through a top-down strategy, initiated by the Israeli Council for Higher Education since the end of 1999. This top-down strategy has created a systemic change that will affect the many layers of university activities rather than in a random, sporadic manner undertaken by enthusiastic individuals. This article discusses the built-in contradictions and dilemmas in the process of adapting distance teaching methods by conventional universities in Israel (as well as in other higher education systems). It examines the merits of a top-down strategy aimed to implement the IT through a macro-level, systemic approach, and analyses the differential uses of the IT in Israeli higher education institutions, relating to variables of: access-outreach; teaching-learning processes; study materials production; data and information retrieval; administrative functions; the creation of researchers communities; inter-institutional collaboration; and associated costs. The article concludes with some suggestions for effective implementation of the IT in different types of higher education institutions in a comprehensive and systematic manner, that will take into account their academic ethos and organizational infrastructure, and cater to the unique needs and characteristics of their relevant constituencies.
\end{abstract}

\section{Introduction}

New information technologies (IT) have moved distance education from the margins to the center stage of higher education worldwide. They prompted nearly all higher education institutions to integrate to some extent various forms of distance teaching (Bates, 1995, 1999; Guri-Rosenblit, 1999a, 2001; Trow, 1999). But new technologies have also presented traditional campus universities with a critical dialectical dilemma. On one hand, many research universities are better equipped than mass-oriented and single-mode distance teaching universities to utilize IT for their benefit. Their advantage is based on their low studentfaculty ratios, richer resources and their ability to use IT for add-on functions to enrich teaching-learning processes, rather than replace their total instructional 
apparatus. On the other hand, the academic ethos of many research universities, which cherish personal academic freedom, institutional autonomy and a selective-elite orientation, oppose the notions of team-work, inter-institutional cooperation and open-door global outreach policies, which characterize the underlying principles and operation of many distance education endeavors.

Research universities are the most dominant sector in Israeli higher education. For fifty years, from 1924 until 1974, they enjoyed a total monopoly and were the only higher education institutions in Israel. The Technion (established in 1924) and the Hebrew University (established in 1925) were shaped on the basis of the German Humboldtian university ideal, premised on unity of research and teaching. The other five university-level institutions, established between 1934 and 1965, tended to follow the model of the two veteran institutions. The research orientation features prominently in Israeli universities. In 1974, the Open University of Israel was established. Differing from the research universities, it was based on the model of the British Open University. In the same year, the first non-university institute, the Rubin Academy of Music and Dance in Jerusalem, was authorized to grant academic degrees in Israel. Since then, Israeli higher education has changed dramatically both in size and composition. When Israel was established in 1948, only three percent of the relevant age cohort were admitted to its two universities. In 2000, over 30 percent of the relevant age cohort studied in higher education institutions (Central Bureau of Statistics, 2000).

The last decade was characterized by rapid change that has shaken the relatively stable and conservative foundations of Israeli higher education. The changes were manifested mainly by tremendous growth in the relevant age cohorts participating in higher education; a fast expansion of the non-university sector; initiation of private colleges; and the "importation" of dozens of extensions of foreign universities. In 1990, about 89,000 students were enrolled in Israel's 21 institutions of higher education: eight universities, six colleges and academies, and seven teacher-training colleges. In 2000, over 200,000 students were enrolled in 54 higher education institutions: eight universities, 24 colleges and academies, and 22 teacher-training colleges (Central Bureau of Statistics, 2000), reflecting an increase of 113 percent over a decade. Among first-degree students, the increase was of 133 percent. In addition in 1999, there were 52 extensions of foreign universities, mainly from the UK and the USA (Kadosh, 1999). This constitutes a drastic restructuring of the Israeli higher education system in a relatively short span of time.

Following these drastic changes over the past decade, the research universities found themselves in a most vulnerable situation. They are still considered to be the strongest and leading institutions of the Israeli higher education, but at the same time they have to compete both for students and funds. They are dreading the deterioration of their status by continuous budget cuts and by increased government intervention in their academic internal affairs. It is important to 
stress that although mainly the Government finances these universities, like most other higher education institutions, they still enjoy full autonomy in academic and administrative matters, albeit within the limits of their budgets. They are not state universities. Except for earmarked grants, they are autonomous to decide what proportion of their budget will be devoted to research or teaching, to graduate or undergraduate programs, to professional schools or science departments. This academic autonomy is vested in the Law of the Council for Higher Education of 1958. The Council for Higher Education was established in 1958 as a buffer body between the Government and the universities in order to control the growth and development of higher education in Israel. In 1974, the Council established the Planning and Budgeting Committee (PBC) that brought into control the allocation of money to higher education institutions. Through its control over the budgets of the various higher education institutions, the PBC exercises tremendous power. It also represents universities' interests, as well as those of other higher education institutes, in negotiating the overall annual higher education budget allocated by the Government.

In the last few years, the Government has threatened the universities' autonomy several times. The latest threat took place in September 2001, when the government decided to change the universities' governing structure and to abolish psychometric examinations as a prerequisite for admission to the universities. The universities are considering a strike against these decisions at the beginning of the next academic year. New developments, including the integration of the new IT, are viewed by many Israeli academics with suspicion, and as additional interventions that might threaten their individual academic freedom.

In 1999, the Council for Higher Education nominated a special sub-committee for enhancing the integration of IT into Israeli higher education, and most particularly into the universities. The Council for Higher Education has realized the importance of IT for enriching the teaching/learning processes, for research purposes and for the development of high tech industry. At the same time, the members of the Council for Higher Education also understood that without obtaining additional funds and being promised other incentives, it was unlikely that the universities would have initiated a systematic approach in their adoption of IT. Thus, in October 1999, the Council for Higher Education published a special competitive call for projects integrating IT aimed at all higher education institutions (Council for Higher Education, 1999). This call encouraged the applying parties to plan the integration of IT into their teaching apparatus, academic management, and administration procedures, thereby rewarding the winning institutions with generous grants. The underlying principles of this top-down strategy are discussed in detail further on.

This article discusses the impact of academic cultures on implementing changes in various national settings. It examines the merits of a top-down strategy aimed to implement the IT through a macro-level, systemic approach, and analyses the differential uses of the IT in Israeli higher education institutions. The discussion 
relates to the variables of: access-outreach; teaching-learning processes; study materials production; data and information retrieval; administrative functions; the creation of researcher communities; inter-institutional collaboration; and associated costs. This article concludes with some suggestions for effective and systematic implementation of IT in different types of higher education institutions that takes into account their academic ethos and organizational infrastructure, while catering to the unique needs and characteristics of their relevant constituencies.

\section{Academic Cultures and Distance Education}

Different academic cultures dominate the operation of various higher education systems. These cultures affect the implementation of changes and the adoption of new traditions and teaching innovations. Clearly, the academic environments of English collegiate universities and liberal arts colleges in the USA differ meaningfully from Humboldtian research-oriented universities (Rothblatt, 1997). As in many other fields, there are also crucial differences between different higher education systems in their attitude towards distance education.

The degree of novelty of distance education at the university level in various higher education systems has influenced the way different distance education institutions have been shaped in various national settings. The UK and Canada, for instance, have a long history of university correspondence teaching dating back to the nineteenth century. The establishment of the British Open University in 1969 and Athabasca University in Canada in 1970 were not perceived as a sharp break with tradition (Guri-Rosenblit, 1999b). Although none of their antecedents offered the precise mix the new universities offered, the notion of distance teaching at tertiary level was nonetheless well established and longpracticed in these two countries.

On the other hand, in most European countries, the concept and practice of distance teaching at university level was novel and revolutionary until the 1970s. Hence, the Spanish UNED and the German FernUniversität decided to be as similar as possible to the traditional universities in their admission policies, curricula and exit requirements, and they had to fight to ensure their academic status and acceptance by their conventional counterparts. In Israel, the Open University has been treated for many years with suspicion by the research universities and has yet to be fully accepted as a peer in the Council of the Universities' Heads.

An additional example relates to the crucial difference between the USA and Europe in the attitude of their higher education systems towards extensions and lifelong learning. In the USA, most universities, and certainly the great public universities, have an extension division that provides courses for adults

International Review of Research in Open and Distance Learning 
in nearly any study (Trow, 1999). This practice is not widely shared among Europeans. Unquestionably, the extension tradition in the USA greatly affects the ways that adult education through IT has developed in the US universities. In addition, the idea of a university that makes profits for its proprietor and shareholders (such as Phoenix University and the National Technology University in the USA) is unthinkable for most Europeans, yet totally acceptable by most Americans.

It follows that the adoption and integration of IT in each national milieu is greatly affected by the overall academic ethos in each country. The perception of academic freedom, for instance, has influenced the operating practices of different distance teaching universities. In Germany, Spain and Israel, where the academic freedom is highly prized and sacred, the notion of teamwork and compulsory quality control mechanisms have been vigorously resisted by many academics (Guri-Rosenblit, 1999b).

Institutions that offer distance teaching or use IT differ enormously in how they were initiated, whom they aim to serve, how they are funded, and the kind of programs they offer. Students and teachers engaged in different kinds of education use the resources of the new technologies differently, influenced by the nature of the subject, the location of the student, purpose of the instruction, etc. (Arnold, 1999; Guri-Rosenblit, 1999c, 2001; Trow, 1999). There are differences influenced also by the various types of institutions within each higher education system. The elite research sector in higher education, the mass-oriented institutions, and the full-fledged distance teaching universities operate on different underlying premises (Daniel, 1996; Guri-Rosenblit, 1999c). The academic goals, potential clienteles, and organizational infrastructure of each of these sectors are immensely diverse, and these profound differences shape the ways in which IT are harnessed in each context to the benefit of variable interest groups. Reaching out to tens of thousands of students is not naturally part of the research universities' agenda. They are inclined retain their elitist oriention for the few and well-to-do students. Their applicants will always exceed the number of places available. The research universities are nonetheless interested in reaching out to some distinct populations outside their campuses, but these are mainly adult postgraduate clienteles working in high tech organizations and in other leading industry enterprises. However, the most impressive and extensive applications of IT in learning processes, at the present time, takes place in the training sectors of the corporate world and in professional continuing education. On the other hand, mass-oriented and distance teaching universities are greatly interested in extending their target populations and utilizing their IT abilities.

The Israeli Council for Higher Education has realized that the dominant academic culture in Israeli universities hinders the application of IT on a wide institutional scale and in a comprehensive manner. As is the case with other research universities, Israeli universities are complex, decentralized organizations, characterized by a high degree of division and diffusion of power. In addition, it

International Review of Research in Open and Distance Learning 
has been quite clear from the experimentation with IT in various places, that to set an appropriate infrastructure for their efficient and effective use is highly expensive. Therefore, it was speculated that with no special funding, utilization of IT in Israeli higher education institutes would be performed by a handful of enthusiasts in a most sporadic pattern. Moreover, the overall reluctance of Israeli academics to allow government to exert external interference in their internal matters has fostered a subtle attitude that decisions to participate in any new effort should be left to the individual academics, and performed in a voluntarily rather than in a compulsory way. All these underlying considerations, taking into account the unique academic culture in the Israeli universities, prompted the Council for Higher Education to issue a call for competitive proposals for designing an overall teaching/learning system based on advanced technologies. The call ensures that the winning parties receive ongoing funding for the proposed experiments for at least two and a half years.

\section{Merits of a Top-Down Strategy}

Universities, in general, as loosely coupled systems, cannot be expected to develop a consistent institutional policy from the academic base only. Given the many changes that Israeli universities have had to face in the last two decades, it was unlikely that any top-down initiative would originate from the universities governing bodies. At the same time, given the entrenched values of institutional autonomy and individual academic freedom, universities tend fiercely to resist any external dictates. The Israeli Council for Higher Education, therefore, had to combine both top-down and bottom-up elements to promote the design and implementation IT policy on a macro level.

The top-down strategy of the Israeli Council for Higher Education in the field of IT utilization aimed at achieving three major goals (Council for Higher Education, 1999):

- To ensure a macro-level institutional approach in implementing IT in each higher education institution;

- To enhance establishment of support centers for the faculty volunteering to implement the new IT into their lectures/seminars and other activities on a stable and ongoing basis, as well as for students.

- To encourage collaboration between several higher education institutions (one of the prerequisites was to submit proposals by at least two collaborating institutions).

Since the call of the Council for Higher Education, published in October 1999, was competitive, it has not compelled anyone unwilling to participate to do 
so. It was, in its essence, a strategy that allowed individual enterprise and entrepreneurship under a top-down sponsorship. The Council devoted \$US 3.8 million for that purpose, and the Ministry of Education, which is directly budgeting the teacher training colleges, devoted a sum of $\$$ US 1.2 million, altogether \$US 5 million for a period of two and a half years.

In addition to the three major goals mentioned above, the call emphasized the importance of additional prerequisites by which different proposals would be evaluated: transferability - the potential of the proposed projects to be transferred to an array of disciplines and other fields of study; scalability the potential of applying any of the proposed experiments on a large scale; and sustainability - the ability to continue any given project at the end of the special budgeting by the Council for Higher Education.

Acknowledging the fact that there are many levels of applying IT in teaching/learning processes, and participating agents may have differential previous experiences with IT, the call stressed that several levels of IT applications would be considered. Levels might range from using the IT as add-on functions in conventional classrooms through substituting part of the face-to-face teaching by technology applications, to delivering courses exclusively through the Internet (Beller \& Or, 2001).

Interestingly, in spite of the inherent reluctance of academics to external interventions, most universities have submitted comprehensive proposals for the application of the IT in many layers of their activities, as did some colleges. Table 1 below presents the number of institutions that submitted proposals and the number of proposals accepted after a careful evaluation of the special subcommittee nominated by the Council for Higher Education, as well as the total number of courses in which IT will be incorporated.

Table 1: Proposals for Implementing IT into the Israeli Higher Education*

\begin{tabular}{|l|c|c|c|c|}
\hline $\begin{array}{l}\text { Type of } \\
\text { institution }\end{array}$ & Total number & $\begin{array}{c}\text { Subrnitting } \\
\text { proposals }\end{array}$ & $\begin{array}{c}\text { Accepted } \\
\text { proposals }\end{array}$ & $\begin{array}{c}\text { Total of } \\
\text { courses }\end{array}$ \\
\hline Universities & 8 & 7 & 6 & 307 \\
\hline Colleges** & 24 & 5 & 2 & 26 \\
\hline Total & 32 & 12 & 8 & 333 \\
\hline
\end{tabular}

* Based on Beller \& Or, 2001, p. 33

** Does not include the 22 teacher training colleges, out of which 6 submitted proposals to the Ministry of Education

As can be seen from Table 1, seven out of the eight universities submitted proposals, and six out of the seven were accepted. A much smaller proportion of 
colleges submitted proposals. The positive and active response of most universities to the call of the Council for Higher Education reflects the attractive appeal of a well-designed top-down strategy, even in institutions that guard vigorously their internal autonomy.

\section{Functional Uses of Information Technologies}

IT are complex in nature and serve a wide array of functions. Quite often the discourse on information technologies can be characterized as suffering from "The Tower of Babel Syndrome" - a confusing language and misleading conclusions, resulting from the fact that people refer to totally different functions and roles while using the same generic terms (Guri-Rosenblit, 2001). One emphasizes the interactivity and communication functions, while another highlights the information retrieval possibilities. Some are excited by the video-conferencing abilities, whereas others focus on the sophistication of text production, the richness of multi-media packages, etc. One application can be relatively inexpensive (such as email communication), while another possibility might be costly (such as a pre-prepared multi-media program). Some abilities of IT may be used with minor alterations of the study environment, while others require major changes in the existing infrastructures. The main uses of IT in Israeli universities, both those that are already in practice and those submitted as proposals in the framework of the call of the Council for Higher Education, are described as follows:

\section{Access-Outreach}

Traditionally, distance education aimed at extending access to higher education. IT facilitate the outreaching to student clienteles beyond the physical university boundaries. Also, the Israeli Council for Higher Education has defined the reaching out to working adults and the promotion of lifelong learning opportunities as important goals. Nevertheless, many research universities are not so eager to significantly increase their student numbers. Subscribing to an elitist-competitive principle, they select the best students from a large number of applicants each year. Motivated by a desire to increase their financial base, they gear most of their outreach programs towards graduate and post-graduate students who are sponsored, by and large, by their employers. Tel-Aviv University's Business Faculty, for example, operates the most successful programs that utilize IT. Many other programs at other universities are at the graduate or professional diplomas levels and in the fields of professional continuing education. In December 2000, for example, an experimental one-year Telemedicine Project was conducted under the auspices of the World Health Organization and Israel Inter-University Computerization Center, which saw eighteen Medi- 
cal Centers from seven different countries (USA, UK, France, Denmark, Sweden, Brazil and Israel) participating in continuing education courses in Paediatrics through teleconferencing and computer mediation.

Bar-Ilan University has established the Virtual Jewish University that offers online courses in Jewish studies to various locations inside and outside Israel. Bar-IIan University plans to expand this activity; it also offers courses to high school students in computer sciences (Jolles, 2000). The Open University of Israel teaches more than 8,000 students in the former Soviet Union states, in addition to 34,000 students in Israel. Most of the course delivery involves self-study materials and traditional tutoring, but part of the teaching/learning process is conducted through video-conferencing and chat groups through computers located either in study centers or in students' homes. The Open University of Israel utilizes IT in a variety of applications in more than 200 courses out of its 450 courses. The courses are offered to its students that are scattered in over 100 centers throughout Israel.

\section{Teaching-Learning Processes}

The call of the Council for Higher Education has purported mainly to integrate IT more fully into the teaching/learning processes at all universities. As previously shown in Table 1 above, accepted proposals relate to the implementation of IT in 333 different courses in six universities and six colleges. Proposals submitted to the Council for Higher Education included various levels of IT utilization in teaching/learning processes. Some replace entirely class encounters by Web-based delivery. But the majority of the proposals substitute only partially the face-to-face meetings in class, adding such enrichment components as: simulations, chats between students and teachers and among students after class, course homepages that contain former exams, detailed syllabi, exercises, relevant connections to data resources, experiments, etc.

The fact is that IT are mostly used in learning/teaching processes at Israeli universities as add-on functions, rather than as a replacement of the lecture or seminar encounters. As in many other single-mode distance-teaching universities, this is also the case even at the Open University of Israel. So far, the new IT has not replaced the overall apparatus of traditional distance teaching. Most online students still receive the relevant textbooks through mail, or are advised to buy their study books and readers in nearby bookstores.

Interestingly, many Israeli academics do not regard teaching through IT as equivalent to enhancing distance education (Jolles, 2000). Some believe that distance education should be performed by open universities, or by special institutions designed to teach students at a distance. IT enables to enrich teaching/learning activities for students on campus and for a handful of students 
outside the campus; but they do not necessarily create a distance teaching environment. Even when offering full online courses, most Israeli academics believe that the overall teaching in a research university should be based on personal encounters in lecture halls or seminar rooms. These encounters are essential for socializing students into the academic world, and for shaping their minds and values.

\section{Study Materials Production}

The production of specially designed self-study materials stood at the heart of the distance teaching universities that were established in the early 1970s and based on the model of the British Open University. Textbooks and study materials produced and developed by the Open University of Israel serve the students at all Israeli universities, because they are often the only university level materials written in Hebrew. The process of developing high quality materials is labor intensive, time consuming and costly. Therefore, dealing with this issue in their specific call for proposals, the Council for Higher Education stressed that the original development of study materials is not the major task of the call, and should be avoided as much as possible. Participants should adopt existing textbooks and materials and adapt them for the use of teaching through the Internet and other IT applications.

Evidently, the new IT enable updating of existing study materials on an ongoing basis and retrieval of information from a wide range of data sources. They also add exciting components into the learning process. Yet thus far, they have not offered an overall solution for replacing most of the textbooks and resource books. Future developments of the e-book, standardization of computer software, and growing student accessibility to personal computers might change this situation. Few submitted proposals dealt with the production of original study materials. In the framework of the call, it was specified that the content of any original development or production will be owned entirely individual inventors. But the instructional design and tools of producing new materials or simulations will be owned by the Council for Higher Education, and that they will hold the copyright to transfer the knowledge to all other higher education institutions.

\section{Data and Information Retrieval}

Unquestionably, English constitutes nowadays the 'academic Esperanto' throughout the world. English proficiency is a prerequisite for completing any degree at an Israeli university or college. The ability of the new technologies to extend the possibilities of data retrieval and information, mainly for English speaking 
students, is one of their important attributes. All university libraries in Israel use a variety of engines for retrieval of information in most disciplines and subject matters. The Union List of Israel (ULI) has connected the catalogues of all university libraries. All university libraries are currently in the process of transforming their existing catalogues into the international MARC format. Students can nowadays access many resources both outside their university and outside Israel. The project of the Council for Higher Education encouraged the universities to extend these activities, and some of the proposals submitted by the universities, referred to various library projects to establish virtual libraries.

\section{Administrative Functions}

IT have the power to facilitate many administrative operations in the field of enrolment, registration, taking examinations, class management, grades, etc. Most Israeli universities, via the Internet, enable the students to enrol, receive and retrieve detailed information as to their prospective fields of studies, loans, fellowships, chances of being admitted, etc. In the teaching process, students can see their exam grades, average grades of their fellow students, exam answers and assignments. It seems that in Israeli universities, IT are currently utilized for administrative purposes on a much larger scale as compared to the teaching/learning processes. Many of the university proposals referred to the growing applications of the IT in their administrative apparatus at many levels: faculty level, schools, and departments.

\section{Researchers' Communities}

IT enhance the creation of researchers' communities, which enable academic communities to transcend institutional boundaries and national borders. It is well known that sometimes academics' loyalty to the international disciplinebased groups exceeds that of their own institution. IT are realizing most scholars' dreams of global access to enormous bodies of information at his/her desk and immediate or frequent interactions with fellow scholars all over the world (Trow, 1999).

Israeli researchers have a long established reputation for being internationally oriented and for collaborating with peers in leading universities in the USA, Europe and other places. Through the use of email, Israelis are participating in various projects and special research tasks initiated by the European Union and Council of Europe, as well as many other research endeavors. The call of the Council for Higher Education encouraged collaboration between scholars from different higher education institutions in Israel. Obviously, the planning of the inter-institutional proposals and their monitoring have been enhanced by the 
A Top Down Strategy to Enhance Information Technologies into Israeli Higher Education

rich avenues of communication that are enabled and facilitated by IT.

\section{Inter-Institutional Collaboration}

Despite its importance, Inter-institutional collaboration contradicts the tendency of many elite-oriented universities to stay aloof and unique. Few collaborative endeavors exist among Israeli universities. Unlike the situation in the USA, Canada and many European countries, there are no standard accreditation procedures in Israel for students transferring from one university to another amidst their studies. There are some collaborative ventures between Israeli universities in various research projects, but no cooperation in the domains of curriculum planning and instruction. The Council for Higher Education realizing the huge investment in setting appropriate infrastructure for the various applications of IT, and the obvious duplications that exist between institutions that insist on being totally independent, it seemed imperative to encourage inter-institutional collaborations. For that reason, in its call to submit proposals, The Council of Higher Education specified for each proposal to be submitted by at least two, and preferably more, institutions.

\section{Associated Costs}

In the face of shrinking budgets, the problem of costs is most pertinent as to the future applications of IT in higher education environments. While IT literature contains many claims of cost efficiency and of providing economiesof-scale compared to traditional classroom teaching, there is little evidence to support these claims in higher education environments. Most of the accumulated evidence provides contradictory results. Implementation of technologies costs more money as compared to previous distance teaching techniques. Since they are used mainly as add-on functions, are labor intensive, and bring the expert teacher back to center stage, they can be costly.

Preparation of an online course may take from four to twenty times more resources as compared to the planning of a regular lecture (Bates, 1999; GuriRosenblit, 1999b). Some people currently teach online for free, because they feel enthusiastic and they are curious to examine the new technologies' possibilities. But institutions cannot rely on such a voluntary readiness demonstrated by all, or most, of their academic faculty. Obviously, until the cost issues related to IT uses are clarified, examined carefully, and transparent, huge gaps will persist between potential abilities of new technologies and their actual implementation.

The Israeli Council for Higher Education tried to circumvent this dilemma by sponsoring part of the new initiatives of IT implementation in most universities

International Review of Research in Open and Distance Learning 
and some colleges, and by promising an ongoing sponsorship for those projects that prove to be successful and endurable.

\section{Concluding Remarks}

New IT have a tremendous potential to change and reshape the academic teaching and learning practices in all types of higher education institutions. They open up possibilities to design new study environments that have not previously been feasible for both on-campus and off-campus students. It seems as though the whole world is currently engaged in discussing the actual and potential effects of the IT abilities and qualities (Evans \& Nation, 2000; Khan, 1997; Littleton \& Light, 1999; Selinger \& Pearson, 1999; Somekh, \& Davis, 1997).

IT offer a real challenge to supplement existing technologies and to provide exciting new possibilities to enrich and improve the quality of the learning process, and to affect the delivery, production and administrative mechanisms of academic systems. So far, the promise of the new technologies is to reshape the learning/teaching processes in most higher education institutions, but there is still a long way to go before its optimal and full realization. Many policy makers, administrators and academics worldwide are currently engaged in applying IT in different domains. But most trials are still operated on a small-scale and are characterized by a sporadic and dispersed nature. Any serious shift of the existing learning infrastructures, therefore, requires an overall institutional commitment, a gradual induction of both students and academic faculty to the new IT uses, the planning of appropriate support services, and clear financial prospects.

In promoting integration of IT into the Israeli higher education institutions using a macro-level systematic approach, and most particularly into the research universities, any large-scale change in higher education systems must be attentive to the dominant academic culture in each national setting. The Israeli Council for Higher Education has employed a top-down approach to extend a competitive call for integrating IT in higher education addressed to all universities and colleges. No policy was imposed upon the universities, but they were encouraged to compete for funds in applying IT into their operations. Such a strategy took into consideration the long-standing reluctance of academics to external intervention, and their sensitivity in relation to their individual academic freedom. In such a way, bottom-up elements were triggered by a top-down initiative, enabling individual enterprise under a central sponsorship. The call has also encouraged inter-institutional collaboration, by making it a prerequisite that submission of proposal be by at least two institutions.

Seven out of eight Israeli universities submitted comprehensive proposals for implementing IT in hundreds of courses, and provided plans for establishing

International Review of Research in Open and Distance Learning 
support services for both professors and students, and for utilizing IT into academic management at the various levels of the university operations. The fact that most universities have responded positively to the call of the Council for Higher Education, and invested efforts in retaining the special funding for incorporating IT into their everyday activities, reflects the inherent advantages of a top-down policy. Even the Israeli universities that value highly their institutional autonomy and vigorously resist external interventions into their internal affairs, have understood that only through a central sponsorship, it might be possible to implement IT in an intelligible and systematic manner. The results of these sponsored projects are yet to be known, since the experiments will end in 2003. All participating parties are expected to present the lessons that they have deduced from the operation of the various applications in a symposium open to the public, and to offer their insights as to future developments in this field to all higher education institutions.

The Israeli case highlights the problematic situation of costs associated with the application of IT in higher education. Many higher education institutions find it difficult to sponsor the experiments and various uses of IT from their operating budgets. Even a relatively inexpensive application such as email, requires many hours of human capital investment. In potential, students can contact their teachers through email 24 hours per day. But the teacher is expected to respond, and it is totally unclear who is going to reward these extra efforts. The major attraction of the Council for Higher Education's call was the promise to fund the different proposals for at least two and a half years. A central intervention of a body, like the Israeli Council for Higher Education, is quite essential for enabling IT uses in the many layers of the university activities. It seems that the cost issue constitutes a most important hindrance for the application of IT on a large scale, and explains partially the fragmented and limited nature of their implementation so far. 
A Top Down Strategy to Enhance Information Technologies into Israeli Higher Education

\section{References}

Arnold, R. (1999). Will distance disappear in distance studies? Preliminary considerations on the didactic relevance of proximity and distance. Journal of Distance Education. 14 (2), pp. 1-9.

Bates, A. W. (1999). Managing technological change: Strategies for academic leaders. San-Francisco: Jossey Bass.

Bates, A.W. (1995). Technology, open learning and distance education. London: Routledge.

Beller, M. and Or, E. (2001). Virtual learning is an existing reality. Academia, 9, pp. 27-34 (in Hebrew).

Central Bureau of Statistics (2000). Education and culture - selected data, based on the Statistical Abstract of Israel 2000, No. 51. Jerusalem: State of Israel Central Bureau of Statistics (in Hebrew).

Council for Higher Education (1999). . call for proposals: Designing an overall teaching/learning system based on advanced technologies. Jerusalem: The Budgeting and Planning Committee of the Council for Higher Education (in Hebrew).

Daniel, J. S. (1996). The mega-universities and the knowledge media. London: Kogan Page.

Evans, T. and Nation, D. (Eds.) (2000). Changing university teaching: Reflections on creating educational technologies. London: Kogan Page.

Guri-Rosenblit, S. (2001). The Tower of Babel syndrome in the discourse on information technologies in higher education. Global E-Journal of Open, Flexible and Distance Education. 1 (1) pp. 28-38.

Guri-Rosenblit, S. (1999a). The agendas of distance teaching universities: Moving from the margins to the center stage of higher education. Higher Education, 37, pp. 281-293.

Guri-Rosenblit, S. (1999b). Distance and campus universities: Tensions and interactions - A comparative study of five countries. Oxford: Pergamon Press and The International Association of Universities.

Guri-Rosenblit, S. (1999c). Differential impacts of information technologies on three academic environments: The elite sector, mass-oriented universities, and distance teaching institutions. A Keynote Address at the Euro-Med Conference on Tele-Technology in Learning Environments, Tel-Aviv, October 1999 .

International Review of Research in Open and Distance Learning 
A Top Down Strategy to Enhance Information Technologies into Israeli Higher Education

Jolles, S. (2000). The use of technologies in Israeli universities: An internal report of the Marketing and Strategic Division. The Open University of Israel (in Hebrew).

Kadosh, F. (1999). Structural changes in the higher education system in Israel in the Nineties, M.A. thesis. Tel-Aviv University, Faculty of Social Sciences.

Khan, B. H. (ed) (1997). Web-based instruction. New Jersey: Prentice Hall.

Littleton, K. \& Light, P. (Eds.) (1999). Learning with computers: Analysing productive interaction. London: Routledge.

Rothblatt, S. (1997). The modern university and its discontents: The fate of Newman's legacies in Britain and America. Cambridge: Cambridge University Press.

Selinger, M. \& Pearson, J. (eds) (1999). Telematics in education: Trends and issues. Oxford: Pergamon Press.

Somekh, B. \& Davis, N. (eds) (1997). Using information technology effectively in teaching and learning London: Routledge.

Trow, M. (1999). Lifelong learning through the new information technologies, Higher Education Policy, 12 (2), 201-217.

Citation Format

Guri-Rosenblit, Sarah (January, 2002) A Top Down Strategy to Enhance Information Technologies into Israeli Higher Education. International Review of Research in Open and Distance Learning: 2, 2. http://www.icaap.org/iuicode?149.2.2.10 